\title{
Afasia como síntoma de presentación de una hepatitis $A$
}

\begin{abstract}
Sara Pérez-Pereda' ${ }^{1}$ Vicente González-Quintanilla' ${ }^{1}$, Juncal Sánchez-Arguianoo ${ }^{2}$, Yesica Jiménez-López ${ }^{1}$
'Servicio de Neurología. Hospital Universitario Marqués de Valdecilla. Santander (Cantabria). España

${ }^{2}$ Servicio de Medicina Intensiva. Hospital Universitario Marqués de Valdecilla. Santander (Cantabria). España
\end{abstract}

Recibido: 11/12/2018

Aceptado: 27/01/2019

En línea: 30/04/2019

Citar como: Pérez-Pereda S, González-Quintanilla V, Sánchez-Arguiano J, Jiménez-López Y. Afasia como síntoma de presentación de una hepatitis A. Rev Esp Casos Clin Med Intern (RECCMI). 2019 (Abr); 4(1): 16-17. doi: 10.32818/reccmi.a4n1a6.

Autor para correspondencia: Sara Pérez-Pereda. sarap.pereda@gmail.com

\section{Palabras clave \\ $\triangleright$ Meningoencefalitis \\ $\triangleright$ Virus de la encefalitis \\ $\triangleright$ Virus de la hepatitis A}

$\triangleright$ Afasia

\begin{abstract}
Resumen
Raramente el virus de la hepatitis A (VHA) se manifiesta con alteraciones neurológicas. Existen casos reportados de síndrome de Guillain-Barré, encefalomielitis aguda diseminada, crisis epilépticas y meningoencefalitis. Los casos de meningoencefalitis presentan algunas características comunes. Su diagnóstico se apoya en la presencia de meningitis linfocitaria con serología IgM VHA positiva. Describimos un caso novedoso por la forma de presentación, hasta ahora no descrita, en el contexto de VHA, con afasia de inicio brusco y aparición de los síntomas digestivos en los días siguientes. Los estudios realizados descartaron otras etiologías, y la evolución fue favorable con tratamiento de soporte.
\end{abstract}

\section{Puntos destacados}

$\triangleright$ El virus de la hepatitis A es raramente tenido en cuenta en el diagnóstico diferencial de las meningoencefalitis agudas.

$\triangleright$ El caso que presentamos pone de manifiesto la importancia de su inclusión en el despistaje infeccioso de las meningoencefalitis víricas.

\section{Introducción}

Las manifestaciones neurológicas del virus de la hepatitis A (VHA) son muy poco frecuentes. Se han reportado casos de síndrome de Guillain-Barré', encefalomielitis aguda diseminada ${ }^{2}$, crisis epilépticas ${ }^{3}$ y meningoencefalitis ${ }^{4-8}$. El mecanismo por el cual se producen estas alteraciones neurológicas no es bien conocido. Algunos autores abogan por que son debidas a alteraciones metabólicas secundarias al daño hepático, mientras que otros creen que existe una invasión directa del sistema nervioso central por parte del virus. Los pocos casos descritos de meningoencefalitis presentan algunos rasgos comunes: a) existencia de un cuadro pseudogripal prodrómico seguido en un periodo de días de disminución del nivel de consciencia y/o confusión como síntomas más frecuentes; b) pleocitosis linfocitaria en líquido cefalorraquídeo (LCR); c) ausencia de hallazgos patológicos en resonancia magnética (RM) craneal excepto un único caso de realce meníngeo focal ${ }^{8}$; d) electroencefalograma (EEG) con lentificación de la actividad cerebral; e) serología IgM VHA positiva; y f) evolución clínica favorable.

Describimos un nuevo caso de meningoencefalitis en probable relación con VHA de presentación atípica. Explicamos los hallazgos clínicos, de neuroimagen, electroencefalográficos y de laboratorio que apoyan el diagnóstico, y reiteramos la necesidad de incluir el VHA dentro del diagnóstico diferencial de las meningoencefalitis agudas.

\section{Historia clínica}

Mujer de 38 años sin hábitos tóxicos ni antecedentes médicos de interés que, tras un cuadro de 2-3 días de evolución de cefalea y malestar general, acudió al 
hospital por clínica de confusión y alteración del lenguaje del despertar. En el momento de la valoración neurológica presentaba un buen nivel de consciencia, inquietud, inatención y afasia mixta moderada con lenguaje poco fluido, anomia, emisión de abundantes parafasias y dificultad para la comprensión de órdenes semicomplejas, sin otra focalidad neurológica ni signos meníngeos. En la exploración sistémica, no se constató fiebre, ictericia ni ningún otro signo de interés.

\section{Pruebas complementarias}

Ante un cuadro de alteración del lenguaje del despertar, se activó el protocolo de código ictus, resultando normales la tomografía computarizada (TC) craneal, la angio-TC y el estudio de perfusión. Descartado un origen vascular, y considerando los pródromos virales, se realizó punción lumbar con obtención de LCR claro a presión normal, con 25 células $/ \mathrm{mm}^{3}$ (0-6), siendo el $85 \%$ mononucleares (0-0), proteínas $128 \mathrm{mg} / \mathrm{dl}$ (20-50) y glucosa $64 \mathrm{mg} / \mathrm{dl}$ (50-80) con 95 mg/dl en sangre (70-110). En este momento, siendo la principal sospecha una meningoencefalitis aguda, probablemente vírica, con afasia como síntoma neurológico deficitario, se decidió iniciar tratamiento empírico con aciclovir. Al día siguiente, persistiendo una afasia mixta moderada, se realizó EEG que mostraba actividad de fondo normal y ausencia de anomalías focales. En el estudio analítico de rutina, se obtuvieron pruebas de función hepática (PFH) patológicas con AST 4.014 U/I (2-37); ALT 6.204 U/I (2-40); gamma-GT $172 \mathrm{U} / \mathrm{I}$ (11-50); fosfatasa alcalina $139 \mathrm{U} / \mathrm{l}$ (40-129); bilirrubina total 2,8 mg/dl $(0,1-1,2)$; y amonio normal 21 mol// (11-48), compatibles con hepatitis aguda.

\section{Evolución}

La exploración física continuaba siendo anodina, sin presencia de dolor abdominal, hepatoesplenomegalia ni ascitis. Se realizó una ecografía abdominal que descartó lesiones estructurales hepáticas. Al tercer día de ingreso, la paciente comenzó a presentar ictericia, náuseas y vómitos. Se obtuvieron PCR de enterovirus, virus del herpes simple (VHS) 1 y 2, y cultivos negativos en LCR, por lo que se suspendió el aciclovir. Los frotis faríngeos de influenza A y B fueron también negativos, así como las serologías de Toxoplasma, Brucella, citomegalovirus (CMV), virus de Epstein-Barr (VEB), VHS 1 y 2, virus de varicela zóster (WZ), Borrelia, virus de la inmunodeficiencia humana $(\mathrm{VIH})$, y virus de las hepatitis $B$ y $C$. Parvovirus B12 no fue testado. Sin embargo, se obtuvo una serología VHA tanto IgM como IgG positiva, revelando una infección activa por VHA. La determinación de VHA (PCR o carga viral) en LCR no se realizó, ya que es una técnica que no está disponible en nuestro laboratorio de referencia. La paciente negó viajes recientes, vacunaciones, posible consumo de tóxicos o aguas contaminadas, ni contacto con animales o pacientes enfermos. La RM cerebral resultó normal. Se mantuvo únicamente tratamiento de soporte, y la alteración del lenguaje se fue resolviendo hasta quedar asintomática al tercer día de ingreso, y las PFH fueron mejorando paulatinamente. Al séptimo día, fue dada de alta.

\section{Diagnóstico}

Meningoencefalitis aguda por virus de la hepatitis A.

\section{Discusión y conclusiones}

Desde nuestro conocimiento, se trata del primer caso de meningoencefalitis asociada a hepatitis A con afasia como manifestación inicial. Las serologías y cultivos microbiológicos permitieron descartar otros posibles agentes virales implicados, principalmente los más frecuentes causantes de meningoencefalitis víricas, enterovirus y virus herpes, y otros que pueden cursar con afectación hepática y neurológica como el CMV. El EEG de nuestra paciente no mostró enlentecimiento de la actividad cerebral frente a lo encontrado en la mayoría de los casos previamente reportados ${ }^{4,6-8}$, lo cual descarta la posibilidad de encefalopatía secundaria a infección sistémica. En nuestro caso, la normalidad del EEG, la existencia de una franca focalidad neurológica con preservación del nivel de consciencia y la pleocitosis linfocitaria en el LCR, permitieron confirmar el diagnóstico de meningoencefalitis aguda en el contexto de una infección activa por VHA. Aunque no se pudo detectar ADN del virus mediante PCR en LCR, no existen datos acerca de la sensibilidad de esta técnica en la detección del VHA y los casos reportados hasta la fecha se apoyan en la determinación de anticuerpos séricos. Dado que el cuadro pseudogripal previo es inespecífico, y que la ictericia y la clínica digestiva pueden ser manifestaciones más tardías que las neurológicas, la infección activa por VHA puede pasar inadvertida. Concluimos que posiblemente la incidencia de meningoencefalitis por VHA esté infraestimada y debe considerarse dentro del diagnóstico diferencial de las meningoencefalitis víricas, tanto del adulto como de la edad pediátrica, incluso en ausencia de factores epidemiológicos predisponentes.

\section{Bibliografía}

1. Chitambar SD, Fadnis RS, Joshi MS, Habbu A, Bhatia SG. Case report: hepatitis A preceding Guillain-Barré syndrome. J Med Virol. 2006 Aug; 78(8): 1011-1014.

2. Valenzuela Jl, Rodríguez J, Dennis R, Novoa D, Barrera E, Gómez CC. Encefalomielitis aguda diseminada en el adulto. Caso de asociación con infección por el virus de la hepatitis A. Acta Med Colomb. 2014; 39(1): 64-68. Accesible en: http://www.actamedicacolombiana.com/cont. php?id=228\&id2=2092

3. Cam S, Ertem D, Koroglu OA, Pehlivanoglu E. Hepatitis A virus infection presenting with seizures. Pediatr Infect Dis J. 2005 Jul; 24(7): 652-653.

4. Bromberg K, Newhall DN, Peter G. Hepatitis A and meningoencephalitis. JAMA. 1982 Feb 12; 247(6): 815.

5. Davoudi S, Soudbakhsh A, Emadikouchak H, Nikbakht G, Modabbernia A. Meningoencephalitis associated with hepatitis $A$ infection: a case report and review of literature. Trop Doct. 2010 Jul; 40(3): 176-7. doi: 10.1258/ td.2010.090424.

6. Ghorbani G, Ameli J, Ghadimi H, Form A. Meningoencephalitis of hepatitis A in adult man: a case report. Hepat Mon. 2008; 8(4): 313-316. Accesible en: http://hepatmon.com/en/articles/70018.html

7. Leblebicioglu H, Esen S, Sünbül M, Saniç A, Günaydin M. Acute hepatitis a virus infection and meningoencephalitis. Annals of Saudi Medicine. 1997; 17(1): 86-87. doi: 10.5144/0256-4947.1997.86.

8. Mathew T, Aroor S, Nadig R, Sarma G. Focal meningoencephalitis of hepatitis A: a clinico-radiologic picture. Pediatr Neurol. 2012 Sep; 47(3): 222223. doi: 10.1016/j.pediatrneurol.2012.05.023. 